\title{
A clínica da atividade no Brasil: por uma outra psicologia do trabalho
}

\author{
Cristiane Lisbôa da Conceição* \\ Roberta Pereira Furtado da Rosa** \\ Claudia Osorio da Silva ${ }^{* * *}$
}

\begin{abstract}
Resumo
Este artigo tem como proposta explorar um campo de coerência para a psicologia do trabalho no Brasil por meio de algumas pesquisas em clínica da atividade. Dentre as heranças que o compõem, destacam-se o campo da saúde do trabalhador e a análise institucional. Também outras referências como Oddone, Wisner e Canguilhem fazem parte desse campo, marcado por uma multirreferencialidade em que a pesquisa-intervenção se constitui na construção de métodos de análise a partir da situação de trabalho. Afirmamos uma psicologia do trabalho que valoriza a controvérsia como fonte de desenvolvimento de recursos de ofício.

Palavras-Chave: Psicologia do trabalho; Clínica da atividade; Análise institucional; Saúde do trabalhador.
\end{abstract}

\section{La clinique de l'activité au Brésil: pour un autre psychologie du travail}

\section{Résumé}

L'objectif de cet article est d'explorer un champ de cohérence pour la psychologie du travail au Brésil au moyen de certaines recherches en clinique de l'activité. Parmi les héritages qui le composent, se distinguent le domaine de la santé du travailleur et l'analyse institutionnelle. D'autres références comme Oddone, Wisner et Canguilhem font également partie de ce domaine, marqué par une multiréférentialité dans laquelle la recherche-intervention se constitue dans la construction de méthodes d'analyse à partir de la situation de travail. Nous affirmons ainsi une psychologie du travail valorisant la controverse comme source de développement de ressources de métier.

Mots clés: Psychologie du travail; Clinique de l'activité; Analyse institutionnelle; Santé du travailleur.

\section{Introdução}

A clínica da atividade se constituiu na França, nos anos 1990, como uma vertente da psicologia do trabalho. É apresentada por Yves Clot (2010b) como herdeira de uma tradição francófona em que se destacam a psicologia ergonômica desenvolvida por Faverge e Leplat, a ergonomia de Wisner e a psicopatologia do trabalho francesa, com o trabalho de Le Guillant. Na perspectiva da clínica da atividade, o trabalho exerce uma função psicológica, podendo ser fonte de saúde ou adoecimento. No Brasil, ela tem sido assumida em grupos de pesquisa, que, de diferentes modos, a tomam como ferramenta para as suas práticas de pesquisa e intervenção.

Desse modo, temos construído, com a clínica da atividade e outras heranças teóricometodológicas, um campo de coerência que tem dado sentido à prática universitária de pesquisa, ensino e extensão no campo da psicologia do trabalho. Nessa atividade, recentemente nos deparamos com uma questão interessante no grupo de estudantes de graduação da Universidade Federal Fluminense, em Niterói-RJ, que participam de

\footnotetext{
*Endereço eletrônico: cristianelisboa@ gmail.com

***Endereço eletrônico: robertafur@gmail.com

****Endereço eletrônico: claudia.osorio.uff@gmail.com
}

nosso coletivo: um estranhamento e uma dificuldade em definir o que é a psicologia do trabalho. Tomando esse estranhamento como motor da atividade de pesquisa, os estudantes foram em busca de uma definição que estivesse presente no discurso do corpo docente e discente da universidade.

Como resultado, encontraram, é claro, diferentes sentidos possíveis para a psicologia do trabalho, mas gostaríamos de destacar um deles em especial: o discurso que cinde a psicologia entre aquela que cuida da saúde dos trabalhadores e uma outra que gerencia os processos organizacionais.

Nesse artigo, buscamos, a partir do campo de coerência que temos constituído, afirmar um compromisso de romper com esse binarismo, contribuindo para uma renovação da psicologia do trabalho. Com a clínica da atividade, reiteramos uma psicologia tout court, uma psicologia do desenvolvimento humano, coletivo e pessoal, "visto como história". Essa psicologia tem o estudo e a intervenção em situação de trabalho como uma de suas vias de desenvolvimento.

A seguir, acompanharemos alguns fundamentos desse posicionamento, passando pelo 
campo da saúde do trabalhador (MINAYOGOMEZ, 2011), pela análise institucional (LOURAU, 1993) e pelas contribuições de Ivar Oddone, Alain Wisner e Georges Canguilhem²

\section{Saúde do trabalhador e clínica da atividade: mútuas interferências}

Na década de 1990, ao mesmo tempo em que se concebia na França a clínica da atividade, diversos pesquisadores brasileiros procuravam o país com o objetivo de viver experiências de formação. Somava-se a esse fértil encontro o interesse pelas análises dos processos de trabalho, fruto das experiências e conquistas brasileiras no campo da saúde pública e da saúde do trabalhador.

O campo da saúde do trabalhador (ST) abriu caminho e sedimentou uma importante tradição de estudos sobre a relação entre saúde e trabalho no Brasil. Ele emergiu no contexto de transição democrática do início dos anos 1980 (MENDES; DIAS, 1991, MINAYO-GOMEZ; THEDIMCOSTA, 1997), alinhado aos eventos de contestação que ocorriam na Europa já desde o final da década de 1960.

Inserida no campo mais amplo da saúde pública, a saúde do trabalhador tem a Constituição de 1988 como um importante marco, já que nela a execução das ações em prol da saúde do trabalhador é atribuída ao Sistema Único de Saúde (SUS), passando a ser um direito de todos e dever do Estado brasileiro. Tais direitos são reafirmados pela Portaria $\mathrm{n}^{\mathrm{o}} 1.823$ de 2012 que institui a Política Nacional de Saúde do Trabalhador e da Trabalhadora (BRASIL, 2012).

Nos países europeus, a segunda metade da década de 1960 representou um momento de intensa efervescência política onde o sentido do trabalho e da vida foram questionados. Isso ocorreu, entre outras coisas, em decorrência da crise da sociedade de consumo e do esgotamento do modelo organizacional taylorista-fordista (ALLIEZ; FEHER, 1988). Um outro fato relevante diz respeito aos danos causados à vida pela falta de condições adequadas de saúde e segurança no trabalho, que foram tão significativos a ponto de não ficarem muito atrás do grande saldo de mortes decorrentes dos conflitos bélicos ocorridos no mesmo século.

$\mathrm{Na}$ Itália, podemos destacar neste período a atuação do movimento operário, que tinha como propósito combater a nocividade nos ambientes de trabalho. Seu ponto de partida teórico, segundo Barca (2010), era a unidade orgânica e material entre trabalho, ambiente e saúde, construído a partir da noção de que a classe trabalhadora trazia em seus corpos as marcas do desenvolvimento capitalista pós-guerras. Como descreve a autora:

A experiência do ambientalismo do trabalho italiano começou quando uma geração de "especialistas" militantes - médicos, engenheiros e sociólogos do trabalho - começaram a entrar nas fábricas do milagre econômico, ali chamados pelo mesmo movimento sindical na etapa crucial do "Outono quente", e encontraram o conhecimento dos riscos encarnado pelos trabalhadores e as trabalhadoras. Esse primeiro encontro havia sido preparado, por um lado, pelas reflexões sobre a relação entre saber e poder típica do movimento estudantil e, por outro, pela consciência do movimento operário (e da opinião pública) da existência de um enorme problema de saúde / segurança no trabalho causado pelo chamado "milagre econômico" (BARCA, 2010, p.11).

Já a América Latina sente as ressonâncias desses movimentos na década de 1980, quando, como resultado da transnacionalização da economia, torna-se o principal palco de atuação das indústrias pesadas e da poluição ambiental (com o asbesto, chumbo, agrotóxicos, etc.). Desse modo, apontando a centralidade do trabalho na vida moderna, a teoria da determinação social do processo saúde-doença ganha corpo no movimento da Medicina Social Latino-americana, influenciando, em nosso país, o campo da ST.

Segundo Minayo-Gomez e Thedim-Costa (1997), o campo da ST no Brasil representa uma vontade, um compromisso, que entrelaça trabalhadores, profissionais da saúde e pesquisadores, entre outras categorias, em direção a uma mesma meta: a mudança das condições de saúde da população brasileira, especialmente a trabalhadora, entendendo o processo produtivo como fator determinante dessas condições de saúde.

Em síntese, por Saúde do Trabalhador compreende-se um corpo de práticas teóricas interdisciplinares - técnicas, sociais, humanas e interinstitucionais, desenvolvidas por diversos atores situados em lugares sociais distintos e informados por uma perspectiva comum. Essa perspectiva é resultante de todo um patrimônio acumulado no âmbito da Saúde Coletiva, com raízes no movimento da Medicina Social latinoamericana e influenciado significativamente pela experiência italiana. $\mathrm{O}$ avanço científico da 


\section{A clínica da atividade no Brasil: por uma outra psicologia do trabalho}

Medicina Preventiva, da Medicina Social e da Saúde Pública, durante os anos 60 e o início da década de 70, ao suscitar o questionamento das abordagens funcionalistas, ampliou o quadro interpretativo do processo saúde- doença, inclusive em sua articulação com o trabalho (MINAYO-GOMEZ; THEDIM-COSTA, 1997, p.25).

Nesse sentido é importante pontuar que a ST se diferencia do campo da Saúde Ocupacional sucessora da Medicina do Trabalho - na medida em que esta parte de uma visão estritamente biomédica e individualizante das questões de saúde, ou melhor dizendo, das patologias relacionadas ao trabalho. Sendo assim, a Saúde Ocupacional naturaliza as condições de trabalho e os modelos organizacionais, não trazendo para suas análises os processos históricos, políticos e sociais que culminaram nos quadros analisados. Suas intervenções acabam por se restringir a questões pontuais e riscos mais evidentes, como a utilização de equipamentos de proteção individual, o que alimenta uma perspectiva de responsabilização e penalização dos trabalhadores quando as doenças e os acidentes efetivamente ocorrem.

A ST põe em cena avanços significativos no âmbito conceitual que apontam um novo enfoque e novas práticas para lidar com a relação entre saúde e trabalho, embora ainda se observe a hegemonia da Medicina do Trabalho e da Saúde Ocupacional (MINAYO-GOMEZ, 2011). Por isso, a luta dos trabalhadores por melhores condições de vida persiste. Se lançarmos um olhar à história contemporânea, veremos diferentes momentos desta luta pela saúde, que são desdobramentos dos movimentos de ascensão e modulação do capitalismo na humanidade. É claro que tanto a saúde quanto o trabalho são temas que podem ser abordados de diversos modos em diferentes momentos históricos. Mas o capitalismo inaugurou um regime social, político e econômico específico, sob o qual podemos entender esse campo de lutas, pesquisas e intervenções - conhecido no Brasil como saúde do trabalhador - como uma réplica, um colocar em debate (CONCEIÇÃO, 2015).

Isso posto, as pesquisas brasileiras em análise do trabalho ressoam a efervescência das conquistas no campo da ST, do qual muitos pesquisadores que buscaram se aproximar das clínicas do trabalho participaram ativamente. Desde a década de 1990, grupos de pesquisa vêm se constituindo no Brasil, desenvolvendo metodologias e métodos que dão destaque à experiência dos trabalhadores e ao seu protagonismo na busca por melhores condições de trabalho e de vida. Nesses grupos é comum a aproximação de conceitos advindos de diversas tradições acadêmicas, operando múltiplas composições. Assim, em um de seus desenvolvimentos, os conceitos da clínica da atividade se articulam, em novos planos de coerência, com conceitos da vigilância em saúde do trabalhador (OSORIO; MACHADO; MINAYOGOMEZ, 2005; OSORIO; CLOT, 2010) e da análise institucional francesa (OSÓRIO DA SILVA; ZAMBONI; BARROS, 2016). Ou articulam clínica da atividade, saúde do trabalhador e ergologia (SANTORUM, 2006, BARKER, 2005). Outros, no campo da análise do trabalho, sobretudo em saúde e educação, privilegiam articulações com a filosofia, embarcando em inspirações espinosistas que encontramos em textos da clínica da atividade (AMADOR; BARROS; FONSECA, 2016; MAIA, 2006), por vezes fazendo articulações com os trabalhos de Bergson e Deleuze (BARROS; LOUZADA, 2009, 2010; LOUZADA, 2009; TEIXEIRA; BARROS, 2009).

Em um caminho que valoriza o percurso francês, mas segue com características próprias, podemos citar alguns grupos brasileiros e suas especificidades. Alguns destes afirmam seu desenvolvimento na transdisciplinaridade: $\mathrm{N}$ PISTA(s) - Núcleo de Pesquisas Instituições, Subjetivação e Trabalho em Análise(s), na UFRGS; o Núcleo de Estudos e Pesquisas em Subjetividade e Políticas, na UFES; o Nutras - Núcleo de Estudos e Intervenções em Trabalho, Subjetividade e Saúde, na UFF. Outros dialogam com métodos quantitativos e com outras correntes da psicologia do trabalho como o GEPET - Grupo de Estudos e Pesquisas sobre o Trabalho, na UFRN. E outros ainda se situam em núcleos de pesquisa fora da psicologia, na linguística ou na educação como, por exemplo, as pesquisas do Grupo de Pesquisas Pensamento e Linguagem (GPPL - Unicamp), do grupo de Linguística Aplicada e Estudos da Linguagem (LAEL - PUC-SP) e dos grupos Análise da Linguagem, Trabalho Educacional e suas Relações (ALTER-USP) e Linguagem, Atividade e Desenvolvimento Humano (LAD'HumanoUTFPR), entre outros.

Vale lembrar que para a clínica da atividade, no "exercício profissional, um funcionamento nunca é idêntico, até mesmo em situação estabilizada" (CLOT, 2010a, p.29). Toda 
repetição comporta uma singularidade, ou seja, toda a atividade, inclusive a do pesquisador ou analista do trabalho, se expressa de forma única em função de seu endereçamento, jamais encontrando situações e/ou destinatários idênticos. Desse modo, a clínica da atividade em nosso país está a serviço de uma outra história, a brasileira. Clot reconhece este movimento no prefácio do livro de Rosemberg, Ronchi Filho e Barros (2014), que apresenta a produção de um grupo de pesquisa brasileiro sobre o trabalho docente:

Vale dizer que não considero este livro como uma "aplicação" da Clínica da Atividade, no Brasil. Essa seria uma ideia desastrosa. Os textos que seguem, como encantadoramente o enuncia um deles, "sujam" a Clínica da Atividade perturbando a geografia de suas paisagens sedimentadas graças a uma outra história que não a história francesa. Felizmente, para nós, para todos nós, brasileiros e franceses (CLOT, 2014, p.12).

Desse modo, os pesquisadores brasileiros utilizam a clínica da atividade como recurso para sua ação, partindo dos obstáculos que enfrentam em seus contextos e de suas controvérsias herdadas de um patrimônio histórico singular. Sobre esse patrimônio, um primeiro ponto a se explorar é sobre a psicologia do trabalho no Brasil.

\section{Por uma outra psicologia... na qual o trabalho é operador de saúde}

Se a constituição da psicologia do trabalho no mundo, segundo autores como Zanelli e Bastos (2004), está associada ao processo de industrialização, que ocorria de forma crescente nos países que se destacavam no cenário ocidental no fim do século XIX e início do século XX, no Brasil sua gestação ocorreu em condições similares. Neste caso, associada a uma demanda de racionalização e controle dos processos produtivos em pleno processo de transformação de um país de economia agroexportadora para um país em industrialização (ZANELLI, BASTOS, 2004). Assim, ela surge enquanto uma psicologia a serviço da Organização Científica do Trabalho (OCT) e ganha legitimidade antes mesmo do reconhecimento legal da profissão em nosso país, o que ocorre na década de 1960.

Desse modo, como um fenômeno global, a psicologia do trabalho se estabelece como uma psicologia industrial, uma psicotécnica, compondo um arsenal de ferramentas para gestão da mão-de- obra. Sendo assim, até a primeira metade do século $\mathrm{XX}$, as atividades dos psicólogos brasileiros eram, predominantemente, relacionadas à seleção de pessoal, ou seja, "não ultrapassavam o recrutamento, a seleção, o treinamento, a análise ocupacional e a avaliação de desempenho" (ZANELLI, BASTOS, 2004, p. 474).

Muitas críticas foram elaboradas a essa psicologia - que se destacava no contexto norteamericano - e ao seu princípio do "homem certo no lugar certo", apontando, de um modo geral, que sua prática está a serviço da exploração e da alienação dos trabalhadores. Na França, a psicologia cognitiva, a ergonomia e a psicopatologia do trabalho, cada uma a seu modo, cumpriram essa função crítica, desenvolvendo um leque de ferramentas, teorias e possibilidades de atuação para o psicólogo do trabalho. Como aponta Clot:

[...] a psicologia do trabalho jamais se voltou completamente para a psicologia industrial "à americana". Certamente há a psicologia industrial clássica na França, mas é menos forte que em outros países da Europa; não é, por exemplo, como na Espanha e na Alemanha. A originalidade francesa é muito forte. Na França há duas razões para a psicologia do trabalho não se transformar na psicologia industrial [...]. Há, então, duas raízes muito fortes: psicopatologia do trabalho e ergonomia. Elas protegeram, poderíamos assim dizer, a disciplina psicologia do trabalho da psicologia industrial (CLOT, 2006, p.100).

No Brasil, como afirma Codo (1984), os psicólogos críticos à psicologia industrial tenderam a evitar a área do trabalho, referindo-se a ela como uma espécie de irmã menor da psicologia, ou uma especialidade daqueles que se vendem às leis do capital. Nesse ponto, apostamos, como o autor, na importância de ocupar, enquanto psicólogos, nosso lugar na fábrica, a partir do qual é possível sustentar, junto aos trabalhadores, a viabilidade dos ofícios operarem na saúde (CLOT, 2013).

Apesar das críticas, a psicologia industrial teve várias linhas teóricas e uma profícua produção de práticas que tinham em comum o olhar sobre o posto de trabalho. Entretanto, tais técnicas começaram a entrar em declínio à medida que os psicólogos passaram a discutir a estrutura das organizações (SAMPAIO, 1998). Ampliando, então, o escopo de análise, a psicologia organizacional passa a se preocupar também com as relações humanas e toma a organização como um 


\section{A clínica da atividade no Brasil: por uma outra psicologia do trabalho}

sistema social complexo.

Por outro lado, a psicologia organizacional dá continuidade ao caráter essencialmente instrumental da psicologia industrial, "supervalorizando as teorias comportamentais na Psicologia, que maximizam a influência do ambiente no comportamento humano e minimizam as influências intrapsíquicas" (SAMPAIO, 1998, p.24). Desse modo, como afirma, Bendassolli:

A psicologia industrial está metateoricamente vinculada ao conceito de realidade objetiva, especificamente ao de comportamento observável, submetido a relações de causa e efeito. O que pode ter mudado, especialmente nas últimas cinco ou seis décadas, com sua aproximação da psicologia organizacional, é o deslocamento para uma concepção cognitivista do sujeito - embora mantendo, provavelmente, as mesmas bases epistemológicas do realismo (BENDASSOLLI, 2011, p.78).

$\mathrm{Na}$ perspectiva realista, conhecer refere-se ao ato de acessar a realidade; uma realidade dada, sobre a qual construiríamos uma representação fidedigna. Qualquer distorção seria um falso julgamento ou uma falha do nosso sistema de percepção e representação do mundo. Para que não ocorram esses enganos, o pesquisador - em sua tarefa científica de desvelar a verdadeira natureza do real - adota, então, uma postura neutra e distanciada do seu objeto de estudo, passando a produzir conhecimento a partir de experiências de laboratório. De modo geral, essa perspectiva é encontrada nas abordagens positivistas, que orientam tanto a psicologia industrial quanto a organizacional.

Por outro lado, a clínica da atividade, e as demais clínicas do trabalho, de um modo geral, são tradicionalmente críticas quanto ao ideal de neutralidade do pesquisador/analista, trazendo ao debate os efeitos produzidos pela observação, enquanto método de pesquisa, naquele que é observado. Para Clot, a observação implica um duplo movimento a ser acompanhado: ela produz conhecimento sobre a atividade de trabalho para o pesquisador, mas principalmente, produz uma atividade no observado, ou seja, "o observado procura se apresentar da melhor forma possível, e representar aquilo que o outro quer ver. $\mathrm{E}$ isso provoca alguma coisa que não se vê, que é o diálogo interior do trabalhador, se observando no momento mesmo em que os outros o observam" (CLOT, 2010b, p.224). A transformação que a observação produz, a interferência do pesquisador no campo pesquisado, é um efeito tomado em sua positividade.

Além disso, as clínicas do trabalho também afirmam em suas análises, por meio do conceito de atividade, um real que é muito mais amplo do que o comportamento observável do trabalhador. Sobre este ponto, a herança de Wisner e da ergonomia francesa de modo amplo são fundamentais, já que, nos contextos reais de trabalho e pesquisa, a tríade saber-prever-agir não é encarada como passos sequenciais da prática analítica, considerando-se a realidade apenas parcialmente previsível.

Desse modo, a atividade real, para Wisner, nada teria a ver com a perspectiva realista. Ele rejeita os modelos simplificados e arbitrários de produção de conhecimento, sempre afirmando haver uma "relação dialética entre o estudo de campo e a experimentação, [...] no sentido de que o método experimental não podia partir da ideia imprecisa de um pesquisador a respeito do que se passa na situação concreta" (WISNER apud CLOT, 2010a, p.54). Assim, Clot, junto a Wisner, questiona o experimentalismo, propondo, para a psicologia do trabalho, o estudo das situações concretas.

Próxima dessa concepção também está a psicologia defendida por Oddone, um importante representante do Movimento Operário Italiano (MOI). Isso porque Oddone e sua equipe acreditavam que o encontro do operário com seu posto de trabalho produz uma experiência crucial para transformação dos ambientes de trabalho. A questão fundamental de Oddone (2007) era como produzir um intercâmbio, uma comunicação, entre a linguagem médica e a linguagem operária/sindical. Ele passa a concentrar seus esforços no sentido de construir uma linguagem nova que pudesse servir de interface. Algumas ferramentas produzidas pelo MOI que possibilitaram trilhar esse caminho foram a técnica de construção de mapas de risco e o método de instruções ao sósia. Elas permitem enxergar os trabalhadores como sujeitos ricos de uma experiência que o analista não tem e ao mesmo tempo fabricar uma linguagem comum que possibilita formalizar e transmitir os saberes da experiência.

Por meio dessa construção, Oddone e sua equipe se dedicaram, portanto, a "fazer de outra maneira a psicologia do trabalho" (CLOT, 2010a, p.84), buscando a via da superação dos obstáculos que se colocam nas situações concretas, ao invés de 
apenas protestar por melhores condições ou barganhar compensações financeiras. Nessa psicologia, que reconhece que aquele que trabalha é o que melhor pode falar do trabalho em questão, a objetividade e a neutralidade positivistas não fazem sentido. Como poderia o analista do trabalho / pesquisador desvelar o real dos contextos de trabalho? Pela via sugerida por Oddone, não há o que desvelar, só há o que inventar. Nossa tarefa consiste, então, em inventar estratégias com os trabalhadores, construindo junto e ampliando, assim, o raio de ação de ambos, analistas e trabalhadores.

Seguindo essas pistas,

[...] diríamos que as metodologias de pesquisa que operamos no campo do trabalho, afirmam um construtivismo radical (CLOT, 2008a; BARROS; LOUZADA, 2009). Buscam não suas regularidades a partir de hipóteses e variáveis controladas, mas ressaltam as possibilidades de divergir, os movimentos de inventividade do viver, num constante processo de diferenciação que se atualiza nos cotidianos dos trabalhadores em situação concreta. E para isso é necessário colocar-se no campo de outro modo, é necessário produzir os dados (e não coletá-los), pois não se considera a existência de um mundo do trabalho (ou mundos do trabalho) que estaria aí pronto a ser desvendado (OSORIO DA SILVA; BARROS; LOUZADA, 2011, p. 197).

É importante notar que essa construção empreendida na análise da atividade se produz no diálogo entre os trabalhadores e os analistas/pesquisadores, ou seja, estes descartam o papel de especialista, como aquele que vai orientar os trabalhadores sobre os melhores modos de agir no trabalho. Atuar dessa maneira seria cair em uma ilusão cientificista, que, como denuncia Canguilhem, possui "a pretensão de deduzir e comandar todo o progresso humano a partir unicamente do progresso do conhecimento científico" (2001, p.111). Esse modo de pensar desconsidera a possibilidade de escolha dos indivíduos e embarca na racionalização concebida por Taylor na OCT.

Entretanto, a atividade de trabalho sempre implica escolhas, mais precisamente, na atividade, várias ações rivais entram em disputa, concorrem entre si, nessa atuação somente uma dessas ações se realizará. A ilusão da racionalidade científica, especificamente aquela referida ao trabalho predominantemente industrial, é a expectativa de prever e controlar a iniciativa operária por meio de métodos que privilegiam a matematização da experiência. É assim que, como nos explica Canguilhem a partir de análise do trabalho de Friedmann ${ }^{3}$, essa racionalização, assumida por exemplo pela psicotécnica ao tomar o homem como objeto, choca-se com a resistência da subjetividade humana:

O comportamento operário se revela como um dado rebelde à previsão e ao cálculo. A prática operária de restrição de rendimento é um sintoma da não integração do operário à empresa. Acredita-se poder remediar isso pelo desenvolvimento dos serviços sociais, clubes, sociedades esportivas. Mas é claro que a insuficiência destas práticas revela a incapacidade em que se encontram os investigadores ("enquêteurs"), agentes a serviço da empresa, de ver a empresa com olhos de operários, de ver a empresa na sociedade, no lugar de fazer coincidir a sociedade e a empresa. Os motivos da resistência operária à racionalização são qualificados de irracionais, isto é, finalmente, de anormais (CANGUILHEM, 2001, p.120).

Desse modo, essa racionalização científica, ao se acreditar absoluta, cai na ilusão dos universais, esquece-se que existem outros sentidos e outros objetivos, que não o lucro, a se realizarem por meio do trabalho. Como lembra o autor: "Não há, portanto, uma racionalização, mas racionalizações" (CANGUILHEM, 2001, p.113). Seria, então, a racionalização operária uma anomalia? A divisão entre a concepção e a execução do trabalho nos responde implicitamente que sim. Mas é importante lembrar que essas racionalizações, ao fabricarem diferentes normas, encontram sua diversidade na pluralidade de valores em jogo em toda organização econômica, política e social.

Afinal, os valores que davam sua forma de normas aos resultados da cronometragem taylorista, encontravam-se presentes, mesmo que latentes, porque não discutidos, no pensamento de Taylor, em um certo momento do progresso capitalista na América do Norte, quando em período de abundância de mão-deobra, todo operário que não se dobrasse à pretendida norma (the one best away) era automaticamente despedido. Os problemas de aptidões individuais, do normal individual e do normal coletivo para uma classe que não fosse a dos empregadores não se colocavam (CANGUILHEM, 2001, p.118). 
A clínica da atividade no Brasil: por uma outra psicologia do trabalho

Nessa variedade de normas e valores, é notória a dificuldade na definição daquilo que é considerado normal. Para Canguilhem, o "normal" não tem sentido absoluto, é um termo ambíguo e só pode ser pensado na relação entre o vivente e meio. Afinal, como defender que tal vivente, ou que tal ação, é ideal, se não no seu sucesso em reproduzir sua existência em determinada situação concreta? Nessa perspectiva, não há a priori forma bemsucedida ou falhada, não há normal ou patológico em si. Sendo o meio sempre infiel, a normalidade se faz quando a vida ensaia possibilidades, testa novidades, e o patológico ocorreria, na verdade, na tentativa de suportar passivamente as mudanças do meio. A racionalidade operária é, assim, o modo dos trabalhadores persistirem na sua existência.

Aqui afirmamos uma aposta clínica, que, mais precisamente, busca adaptar o trabalho ao homem - e não o contrário -, por meio de uma transformação protagonizada pelos trabalhadores. Afasta-se, dessa forma, qualquer possibilidade de o analista do trabalho cooperar com a imposição de uma ordem social pré-estabelecida, pois sua prática implica assumir que "ser normal não é ser adaptado à situação, mas ser criador de normas. Ser normal não é ser conformado" (CLOT, 2008, p. 67). Para sustentar esse protagonismo é preciso, como nos fala Clot inspirado em Tosquelles, cuidar do trabalho e não dos indivíduos. Cuidar, neste contexto, significa pôr em ação, chamar à atividade, à construção coletiva de recursos para a ação, de modo que "cuidar do trabalho é transformar a organização do trabalho" (CLOT, 2010b, p.222). É por essa via que podemos conceber o trabalho em seu aspecto positivo, como um operador de saúde (OSORIO DA SILVA; RAMMINGER, 2014), o que não significa negar a nocividade dos modos de organização do trabalho hegemônicos, mas assumir um compromisso coletivo de ampliar a potência normativa dos trabalhadores, frequentemente amputada nesta conjuntura.

Podemos, ainda nessa linha, assumir uma função social conquistada pelo coletivo de análise do trabalho por meio das intervenções em clínica da atividade. Trata-se de fazer com que o ponto de vista do trabalhador, essa racionalização operária, seja levada em consideração, exercendo influência na organização do trabalho. Conforme Oddone, não devemos nos esquivar de tal compromisso apesar do difícil caminho que devemos percorrer para conquistá-lo.
Ao elaborar o método de instruções ao sósia, o médico e psicólogo italiano buscou cumprir com esses compromissos, fazendo de uma questão técnica uma questão ética. Desse modo, ele propôs a multiplicação das instruções sobre determinada situação de trabalho: além daquelas que vêm da chefia, fez emergir, com o método, instruções produzidas a partir da operacionalização do trabalho. Com isso, buscou formalizar e transmitir a experiência profissional, o que faz saltar aos olhos tudo que os trabalhadores fazem para que o trabalho efetivamente se realize.

Por isso, é preciso também ver o trabalho como uma instância de saúde e de subversão, onde, para além da execução, instituem-se novas normas de vida, criam-se novos meios. A atividade de trabalho não é uma reação ao meio, "Ela livra correndo sempre o risco de fracassar nessa tentativa - o sujeito das dependências da situação concreta e subordina a si o contexto em questão" (CLOT, 2010a, p.8). Como nas catacreses, onde os trabalhadores atribuem novas funções aos seus instrumentos de trabalho com o objetivo de realizar a tarefa da melhor maneira possível. Em atividade, os trabalhadores desenvolvem os objetos, os destinatários, os instrumentos, e a si mesmos, provando que a eficácia não é inimiga da saúde.

\section{Outras interferências: a análise institucional}

Apostando no desenvolvimento, a função do analista do trabalho em clínica da atividade seria a implementação de dispositivos metodológicos, construídos a partir de uma "coelaboração", que almeja tornar-se instrumento para a ação dos próprios trabalhadores. Isso significa buscar produzir uma atividade sobre a atividade, ou seja, fazer com que o trabalho seja objeto da atividade de pensamento, ou objeto do cuidado. Significa, também, sustentar uma espécie de "cooperação conflitual"4, ou seja, poder usar as divergências como motores do desenvolvimento entre os trabalhadores e entre eles e a organização do trabalho, a partir da discussão das controvérsias de ofício e da qualidade do trabalho bem feito. Cuidando do trabalho, os trabalhadores cuidam de si e encontram a saúde no desenvolvimento dos recursos coletivos para ação.

Desse modo, ao afirmar o protagonismo dos trabalhadores nessa análise que se dá entre trabalhadores e analistas, a clínica da atividade interpela o próprio papel de analista, colocando-o 
numa posição de horizontalidade com seu objeto. Com isso, não só questiona o paradigma cientificista, mas nos faz pensar que a análise da atividade dos trabalhadores acompanha a análise da atividade dos analistas / pesquisadores. Afinal, também se faz necessário ampliar os recursos para ação do ofício de analista do trabalho, bem como é desejável que estes possam desenvolver-se em sua atividade. Nesse ponto, a interlocução com a análise institucional é fundamental.

Uma importante ferramenta teórico-prática dessa linha de estudos e intervenções é o conceito de implicação. Segundo Lourau (1993), essa ferramenta traz uma crítica à ideia da neutralidade do pesquisador já que, como um prolongamento do "escândalo psicanalítico" - ao forjar os conceitos de transferência e contratransferência -, busca trazer para cena da análise as relações que envolvem pesquisador e objeto de pesquisa.

[...] a História - e em particular, a história das ciências - nos mostra as implicações do pesquisador em situação de pesquisa como o essencial do trabalho científico (mesmo tais implicações sendo negadas). Por exemplo, os pesquisadores do programa de energia atômica nuclear puderam negar, durante muito tempo, suas implicações e dizer: "isso não existe". Mas, alguns anos após Hiroshima, os mesmos escreveram mil páginas de confissão, onde afirmavam: "somos idiotas". E era tarde demais. Sequer era "científico". A Análise Institucional tenta, timidamente, ser um pouco mais científica. Quer dizer, tenta não fazer um isolamento entre o ato de pesquisar e o momento em que a pesquisa acontece na construção do conhecimento. Quando falamos em implicação com uma pesquisa, nos referimos ao conjunto de condições da pesquisa. Condições inclusive materiais, onde o dinheiro tem uma participação tão "econômica" quanto "libidinal" (LOURAU, 1993, p.16).

Ao mesmo tempo, o conceito de implicação, segundo o autor, tenta explorar um outro campo de coerência que não o da psicanálise. A aparição de um novo campo de coerência se revela na contradição entre uma nova disciplina e o saber instituído. Esse movimento de embate entre saberes acontece a todo momento entre as disciplinas de uma universidade, por exemplo. Foi o que aconteceu com a própria Psicanálise quando era formulada por Freud. O novo, ao questionar o instituído, é entendido como incoerente, como estranho, comportando, assim, um escândalo. O escândalo da análise institucional foi propor a noção de implicação, colocando em xeque, a seu modo, a neutralidade do pesquisador.

Sabemos que a Psicanálise e algumas tendências da Sociologia e da Antropologia há muito se interrogam sobre a posição do pesquisador frente à sua produção. Portanto, não somos nem completamente novos nem originais. Propomos, ao contrário da idéia de "originalidade das idéias", a multireferencialidade. Esta não é sinônimo de pluridisciplinaridade; não é uma mera coleção de disciplinas justapostas. Referese ao apelo a diferentes métodos e ao uso de certos conceitos já existentes, a fim de construir um novo campo de coerência (LOURAU, 1993, p.9-10).

Aqui enxergamos um ponto de contato entre a análise institucional e os comentários de Wisner, feitos logo acima por meio dos escritos de Clot. Para fugir dos reducionismos, construindo uma indissociabilidade entre o estudo de campo e a experimentação, é preciso sustentar a ideia de um real complexo e paradoxal, referenciável somente por meio de múltiplos métodos, conjugados de forma rigorosa. Sobre esta questão, o ergonomista nos presenteia com uma linda imagem:

Não se pode rejeitar nenhuma dessas abordagens. Vou propor uma imagem: a realidade é tão multiforme que é impossível segurá-la com um dedo; para isso, será necessário, no mínimo, utilizar dois e, provavelmente, três ou quatro. Somos levados, cada vez mais, fatalmente a uma abordagem múltipla, mas essa questão é crítica (WISNER apud CLOT, 2010a, p. 55).

A questão é crítica porque não podemos perder o rigor. Lourau também nos atenta para a contradição de uma preocupação simultânea com a multirreferencialidade e a coerência. O caminho, então, seria nunca deixar de realizar uma reflexão teórico-epistemológica da nossa prática científica, papel que a análise de implicações busca cumprir. Desse modo, analisar as implicações envolve colocar em questão as próprias condições de produção do saber, as relações de poder e as forças que atravessam o encontro do pesquisador com o campo pesquisado. Esse movimento é incompatível com o campo de coerência positivista, como afirma o autor:

[...] hipotetizamos ser a implicação 


\section{A clínica da atividade no Brasil: por uma outra psicologia do trabalho}

incompreensível no $\mathrm{C}$ de $\mathrm{C}$ [campo de coerência] herdado; na melhor das hipóteses ou na pior? -, isso dá lugar a mal-entendidos ou a pálidas recuperações neopositivistas [...]. [...], a implicação é integrada, por outros, como instrumento de produção de conhecimento, [...], sem colocar em questão nossas condições de sobrevivência, quer dizer, a instituição científica enquanto realidade social que o observador [...] herda cegamente (LOURAU, 2004, p.217).

Ao interrogarmos essa dimensão política, o lugar em que o psicólogo se coloca e é colocado, ou seja, como aquele autorizado a lidar com a dimensão subjetiva do trabalho, nos jogamos numa experimentação que recusa o lugar de especialista do funcionamento dos humanos em situação de trabalho.

Sendo assim, acompanhamos o questionamento feito por Elizabeth Barros e colegas:

Como recusar a esse "mandato social" que atribui ao psicólogo do trabalho controlar, docilizar, esse "fator humano", fator que indica a inviabilidade de considerar homens e mulheres como máquinas? E mais, se afirmamos a potência da vida, como investir em práticas que não nos anestesiem e nos tornem insensíveis ao que se passa nos mundos do trabalho, insensíveis ao que nos dizem aqueles que se "sujam" cotidianamente nos ambientes laborais. Como nos diz Maia (2006): "tudo uma urgente questão de implicação, pois não fazer escolhas, se deixar levar pelos acontecimentos, já é ter escolhido" (BARROS; LOUZADA; VASCONCELLOS, 2008, p. 16).

Rejeitamos o "especialismo" (CHAUÍ, 1982), bem como a função de "gestão dos riscos psicológicos" (CLOT, 2013) ou qualquer outra proposta conscientizadora ou adaptacionista. Trabalhamos sim com a subjetividade, mas buscando problematizar as relações nas quais estamos enredados, tanto no âmbito da intervenção quanto nas práticas sociais em geral, por meio da análise de implicações. A análise, aqui, é fundamental porque implicado sempre se está, já que não existe sujeito ou grupo sem história. Ao analisar, intensificamos a atividade de pensamento sobre ação (seja de trabalhar ou de pesquisar) por meio da troca de destinatários, motivando, com isso, a produção coletiva de conhecimentos sobre o funcionamento da ação (novamente, seja de trabalhar ou de pesquisar) e possibilitando a emergência de outros modos de agir (mais uma vez, no trabalho e na pesquisa).

Sendo assim, a noção de implicação e sua análise fazem parte do campo de coerência da análise institucional. Mas, para que esse tipo de análise ocorra, é interessante que estejamos atentos àquilo que, em geral, é silenciado, deixado à sombra ou visto como algo de pouca importância. Essas coisas que são "faladas apenas em corredores, cafés, ou na intimidade do casal" (LOURAU, 1993, p.51) revelam as implicações do pesquisador, podendo ser importantes disparadores da análise de implicação.

Nesse processo de pesquisa, uma prática que é problematizada por Lourau como caminho possível para realizar uma análise de implicações é a restituição. A restituição enquanto um conceito da análise institucional visa, em última instância, uma real socialização da pesquisa, se constituindo enquanto uma prática distinta daquela empreendida tradicionalmente pelas ciências humanas - uma devolução de resultados. Segundo Lourau (1993, p.54), a restituição tem suas origens na etnologia colonialista em seu encontro com o processo de descolonização. Nela, geralmente, a população estudada era tratada como um "serviçal doméstico", que, após ser objetificada por esse discurso, pouco sabia sobre o que a partir dela se produzia. Quando muito, recebia, anos mais tarde, um artigo ou um livro publicado pelos responsáveis da pesquisa. Ao contrário, a análise institucional propõe a restituição como um procedimento intrínseco à pesquisa, uma prática real, pessoal e implicada. A pesquisa, assim, não se encerra em sua redação final, mas continua, e pode ser interminável. A população estudada, ao receber a restituição, "se torna uma espécie de "pesquisador-coletivo", produzindo ela também, novas restituições tanto ao pesquisador como ao seu presente social e global. "Isso seria, efetivamente, a socialização da pesquisa" (LOURAU, 1993, p.56).

Desse modo, a noção de restituição, problematizada, coloca em cena a participação da população estudada na produção da pesquisa, questão cara para a clínica da atividade, que preza por uma coanálise da atividade, e para a ST, que busca o protagonismo dos trabalhadores na análise dos processos de trabalho. Fazer com que os trabalhadores se apropriem do status de pesquisador é também o que essas perspectivas procuram, bem como assumem, ou ainda, buscam que as pesquisas sejam intermináveis, ou seja, que produzam efeitos de ressonância no campo provocados pela presença do pesquisador. A transformação está colocada e é 
perseguida pelas intervenções em clínica da atividade:

Neste processo de pesquisa e intervenção o objetivo de transformar é fundamental. O desenvolvimento de recursos para a ação é um objetivo ético. Mas, se trabalho é processo, induzir um aumento de intensidade no processo - transformá-lo - é também uma exigência para que se conheça as características desse processo em um determinado ofício, no exercício do trabalho em uma determinada organização ou equipe (OSORIO DA SILVA, 2014, p.86).

Se, por um lado, tanto para Oddone quanto para os ergonomistas, o objetivo final das intervenções é a transformação das situações de trabalho degradadas (classicamente, também no campo da ST), tem-se afirmado a necessidade de conhecer para transformar, ou construir junto aos trabalhadores conhecimentos que sejam úteis no sentido de ampliar seu raio de ação, para que, então, eles sejam protagonistas da transformação. Por outro lado, os autores da clínica da atividade, na França e no Brasil, têm afirmado a importância da inversão dessa equação apoiada na metodologia histórico-desenvolvimental de Vigotski. Como nos fala Clot:

Ela [a metodologia de Vygotski] é significativa de uma ideia experimental preconcebida bem particular: é necessário "provocar" o desenvolvimento para ser possível estudá-lo. De fato, não sendo acessível por métodos diretos de observação, ele obriga ao emprego de "métodos indiretos" (Vygotski, 1999, 2003). Ele nos impõe a organização das "repetições sem repetição", [...], para ter uma possibilidade de "apreendê-lo". No campo do trabalho o interesse da tradição ergonômica francófona (Béguin \& Weil-Fassina, 1997) consiste em ter insistido sobre o fato de que compreender está destinado a transformar. O que descobrimos é, talvez, a profundidade do problema assim levantado. Com efeito, para compreender o que procuramos compreender, é necessário transformar. Neste aspecto, opera-se, sem dúvida o encontro de duas tradições (CLOT, 2010a, p.192).

Analisar a atividade em clínica da atividade implica ter acesso ao real da atividade, que não se revela pela simples observação do comportamento realizado, mas considerando os efeitos da observação naquele que é observado, ou seja, considerando a produção de um diálogo interno, ou ainda, a produção de uma atividade de pensamento sobre a atividade de trabalho. Desse modo, constroem-se métodos indiretos de intervenção, por meio dos quais organiza-se uma nova atividade, agora de análise, que nada mais é do que uma "repetição sem repetição", ou seja, uma replicação impossivelmente idêntica da atividade de trabalho. São estas repetições que nos conectam aos possíveis não realizados que continuam a exercer influência na atividade em curso. Sendo assim, cabe ao pesquisador/analista do trabalho, diante da necessidade de transformar para conhecer, induzir uma intensificação nesse processo, uma atividade sobre a atividade, sendo uma espécie de catalisador.

Nessa indução do processo, viabilizada pelos métodos indiretos, são produzidos registros da atividade, marcas do trabalho sobre as quais a coanálise se debruçará. São essas marcas que permitem ao trabalhador se apropriar do status de pesquisador, ou seja, assumir o papel de observador da atividade. Ao comentar esses registros, o trabalhador busca em seus interlocutores, seja no analista do trabalho, seja em seus pares, pistas para "defender" sua análise. "Como falar de seu trabalho ao clínico? E como fazê-lo ao dirigir-se ao colega? Ele não busca diretamente em si mesmo, nos seus próprios conhecimentos, mas no outro. Deste modo, ele verá sua própria atividade pelos olhos de outros" (OSORIO DA SILVA, 2014, p.89).

Estando o sentido da atividade diretamente ligado ao seu endereçamento, a troca de interlocutores possibilita a construção de novos sentidos para ação. Assim, essa metodologia tem por objetivo fazer com que os trabalhadores "se liberem, tanto quanto possível, de suas maneiras habituais de pensar e dizer suas atividades" (CLOT, 2010a, p.37), ampliando, com isso, a vitalidade dialógica do plano de possíveis não realizados, ou seja, ampliando o poder de agir 5 .

É interessante destacar que: "Para intensificar os efeitos da entrada do novo interlocutor, o clínico, propõe-se que a análise seja feita em etapas sucessivas, que ampliam as oportunidades para o diálogo interior" (OSORIO DA SILVA, 2014, p.90). Nesse sentido, quanto mais oportunidades forem criadas para se retornar à análise coletiva, melhor. É como se a restituição como movimento para retomar os acontecimentos, em geral excluídos (LOURAU, 1993, p.57) fizesse parte do método de intervenção, já que não se aplica simplesmente uma técnica, mas, a partir dela, criam-se momentos para discutir e rediscutir os processos mobilizados pela intervenção. 


\section{A clínica da atividade no Brasil: por uma outra psicologia do trabalho}

Aliás, a concepção dos métodos, no que diz respeito ao número de etapas ou a que tipo de registros serão utilizados, é feita a cada intervenção planejada. Como nos fala Clot (2007, p.129), a construção de um ambiente duradouro de análise e de ação com os trabalhadores requer uma efetiva "coelaboração", refeita a cada encontro. Desse modo, "para seguir tais proposições não é essencial usar os mesmos dispositivos, os mesmos métodos, já usados anteriormente em clínica da atividade. Ao contrário, novas situações de análise irão exigir novos caminhos, novos métodos" (OSORIO DA SILVA; BARROS; LOUZADA, 2011, p. 200). Assim, para empreender uma análise do trabalho aos moldes da clínica da atividade, é preciso estar atento às suas pistas teórico-metodológicas, que fundamentarão a construção dos métodos, ou, como entende a análise institucional, dos dispositivos de intervenção. É preciso estar atento para não cairmos em uma supervalorização do método em detrimento da metodologia, como apontam Osorio da Silva, Barros e Louzada:

[...] as buscas de trabalhos no Brasil em base de dados bibliográficas, além de outros instrumentos disponíveis na Internet, apresentam algumas surpresas. A expressão "autoconfrontação cruzada" leva o pesquisador a uma quantidade consideravelmente maior de trabalho que a expressão "clínica da atividade". Numa avaliação que merece ser discutida, esse fato parece indicar que há uma supervalorização dos dispositivos em detrimento da sua fundamentação teórico-epistemológica. De todo modo, cabe salientar que o que caracteriza a clínica da atividade como uma corrente de pensamento no âmbito da psicologia do trabalho não é a adoção frequente de dispositivos como o da autoconfrontação cruzada ou aquele das instruções ao sósia. Se esses são usados com frequência é porque essa estratégia se revelou profícua para o desenvolvimento dos conceitos acima apresentados, estes sim centrais para a clínica da atividade (OSORIO DA SILVA; BARROS; LOUZADA, 2011, p. 202).

Sobre essa criação de métodos em clínica da atividade, no Brasil, podemos destacar alguns exemplos, como a concepção da Oficina de Fotos (OSORIO DA SILVA, 2011). Nela, fotografias produzidas no ambiente de trabalho pelos próprios trabalhadores são utilizadas como marcas do trabalho. Outra pesquisa recente (FERREIRA, 2016) utilizou a restituição dos resultados de uma longa pesquisa epidemiológica em ST como dispositivo de análise do trabalho. Ainda uma outra (ALBUQUERQUE, 2010) tomou um espaço coletivo já instituído nos serviços de Saúde Mental, os encontros de supervisão clínico-institucional, como campo de registro e análise da atividade dos profissionais que aí atuavam.

Desse modo, dada a variedade e o ineditismo dessas pesquisas, reafirmamos, como no comentário de Clot, que algumas iniciativas como estas 'sujam' a clínica da atividade reconstruindo seus métodos, e a própria metodologia, a cada encontro com os trabalhadores e suas situações concretas. Sendo assim, a partir de seu patrimônio histórico, certos grupos de pesquisa no Brasil têm afirmado um comum a partir do entrecruzamento da clínica da atividade, a análise institucional e a ST, lançando mão de um novo campo de coerência:

A análise institucional francesa nos propõe a metodologia da pesquisa-intervenção, em que é central o conceito da multirreferencialidade, [...].

O campo da saúde do trabalhador, por sua vez, indica como caminho ora a inter ora a transdisciplinaridade, assumindo que o trabalho como objeto não pode ser analisado por uma única disciplina.

Buscamos então compor um novo campo de coerências em que a perspectiva disciplinar da clínica da atividade, tal como proposta por Yves Clot, se articula a outras (OSORIO DA SILVA, 2016, p.46-47).

Se, segundo Lourau (1993), o escândalo da análise institucional, enquanto novo campo de coerência, tem por finalidade propor a noção de implicação, qual seria o escândalo do campo referido acima? Talvez seja o de fazer da psicologia do trabalho uma clínica - aqui não excluindo outras concepções em Clínica do Trabalho. Como lembram Barros, Louzada e Vasconcellos:

Usualmente, a palavra clínica em psicologia traz um suposto cenário de neutralidade, um palco para os problemas psíquicos, uma composição intimista a meia luz para dar vazão aos dramas individuais. Pensar o trabalho como uma clínica, e uma clínica subjetiva, rompe com essa composição. Esse lugar quase sagrado, intocável, sem cheiro das ruas, das massas é estilhaçado, fazendo-se em mil pedaços, dando voz a uma clínica como produção da diferença, como desabitando o solo dos conflitos "intra- 
psíquicos", tomando a clínica como política (BARROS; LOUZADA; VASCONCELLOS, 2008, p. 16).

Desenvolve-se, assim, no Brasil, uma espécie de novo gênero de atividade, o do clínico do trabalho, na intercessão com vários outros (OSORIO DA SILVA; ZAMBONI; BARROS, 2016). Ao mesmo tempo, constrói-se outra concepção de clínica (e de psicologia!), desestabilizando suas paisagens habituais circunscritas na noção de setting terapêutico e em cenas que incluem um divã. Mas que comum é esse que permite afirmar um novo campo de coerência e caracterizar essa prática como clínica? Sustentamos a ideia de que essa concepção "é sempre clínica, no sentido de que é situada, mas também no sentido de que deve produzir efeitos de desenvolvimento de recursos para a ação e de que o trabalhador é protagonista nessa coanálise" (OSÓRIO DA SILVA, 2016, p.51). E ainda, com Clot ${ }^{6}$, acreditamos que o trabalho clínico envolve a passagem do conhecido ao desconhecido, ou seja, a possibilidade de se desfazer de ideias fixas ou de hábitos que carregam o risco da repetição de velhos conflitos.

É importante pontuar que a afirmação de um comum não deseja produzir um efeito de identidade entre as linhas que formam esse novo campo de coerência. Não nos esqueçamos que, como caracteriza Clot (2008, p.66), a controvérsia é a fonte do coletivo, por isso essas linhas se cruzam afirmando sua diferença e produzindo desvios umas nas outras em alianças transversais. Assim, ampliam seu poder agir podendo contribuir com uma possível renovação na psicologia do trabalho no Brasil, sem fazer dicotomias como as que temos vivenciado entre a psicologia do trabalho de um lado e o campo da saúde do trabalhador, de outro (OSORIO DA SILVA, 2014, p. 96).

\section{Conclusão}

Por fim, gostaríamos de apontar o caráter estético, ou inventivo, da atuação em análise do trabalho pela perspectiva da clínica da atividade. Como explicitamos anteriormente, esta prática abrese à reconstrução cotidiana de métodos e da própria metodologia, já que ela se faz a partir de uma "coelaboração" e de uma coanálise com os trabalhadores. Nesse sentido, como fala Clot sobre o trabalho de Wisner, assumimos o risco de inventar outros modos de administração da prova, ou de fundamentar nossos argumentos, frente à comunidade científica (2010b, p.52), forjando modos de fazer ciência a partir, não do experimento de laboratório, mas da experiência produzida na situação concreta. Ainda citando o trabalho de Wisner, Clot afirma:

Não há, provavelmente, outro setor do conhecimento em que a mesma palavra seja utilizada para designar, simultaneamente, uma arte e uma ciência" (1995, p.104). Daí, sua recusa categórica em considerar a psicologia do trabalho como ciência aplicada. $\mathrm{O}$ oposto é que deve ser promovido: "O trabalho é um dos lugares de constituição da psicologia fundamental" (ibid., p.105). Ele não pode ser um simples campo de aplicação ou de verificação de hipóteses, nem sequer, por exemplo, um terreno de estudo para "revestir" alguns problemas de psicologia teórica. No trabalho, os operadores não fazem o que os psicólogos designam como a "resolução de problemas" e com toda a razão: na realidade cotidiana, "em vez de se limitarem a resolver o problema, eles ainda têm previamente de construí-lo (1995, p.134) (CLOT, 2010a, p.53).

Nós também, enquanto pesquisadores e analistas do trabalho, não nos limitamos à resolução de problemas, mas construímos e reconstruímos tais problemas a cada passo desse amálgama que é pesquisar e intervir. Seguimos, assim, sustentando as controvérsias produzidas a partir da pergunta feita pelos estudantes, "O que é a psicologia do trabalho?", assegurando-nos de que a última palavra nunca seja dita.

Procuramos ferramentas conceituais e metodológicas que nos servem para o desenvolvimento da experiência tanto clínica como de pesquisa de uma outra psicologia do trabalho, marcada pela clínica da atividade. Com elas, buscamos construir métodos de pesquisaintervenção para superpor a atividade ordinária, a fim de transformá-la como meio indispensável para compreender.

\section{Notas}

1 No livro intitulado Avec Vigotski, na Introdução, Clot (1999) aponta em que se ancora a importância dada ao trabalho de Vigotski na clínica da atividade: "En fait, le livre propose, entre autres, du neuf sur deux problèmes essentiels : celui du développement de la personne regardé comme histoire - et non plus 
comme genèse - ; celui des rapports entre affects et concepts dans la vie psychologique. E ainda: "Une autre représentation de l'œuvre de Vygotski devrait en sortir. Sa conception de la psychologie s'accommode mal des frontières que l'histoire de cette discipline a finalement tracées entre psychologie expérimentale, psychologie cognitive, psychologie sociale et psychologie clinique. Quand Vygotski s'intéresse au développement c'est autant à celui des concepts qu'à celui des émotions. Quand il cherche à expliquer les mouvements de la conscience c'est du point de l'inconscient et inversement. Quand il insiste sur les déterminations historico-sociales de l'apprentissage c'est pour comprendre la singularité du développement personnel." Assim, ao falarmos em desenvolvimento em Vigotski não nos interessa retornar às divisões entre desenvolvimento lógico, cultural, afetivo etc.

2 Para uma aproximação com esses três autores podese buscar, além de suas próprias obras, a apresentação feita por Clot em Uma Herança em Discussão, primeira parte do livro Trabalho e Poder de Agir (2010a).

3 Segundo Canguilhem, Friedmann conduziu várias enquetes sobre os problemas da racionalização técnica e do maquinismo; especificamente no trabalho tomado como objeto de análise de Canguilhem "A enquête visa prioritariamente as condições de trabalho nos ateliers (oficinas) da grande indústria da América do Norte e do ocidente europeu, durante a segunda revolução industrial, caracterizada do ponto de vista técnico pelo uso da eletricidade como força motriz e do ponto de vista econômico pela tendência imperialista do capitalismo bancário" (2001, p. 110).

4 Essa expressão foi usada por Clot no III CICA para designar uma atuação clínica que não busca o consenso entre as divergências de determinado grupo, mas que usa essas divergências como motor do desenvolvimento.

$5 \mathrm{O}$ desenvolvimento do poder de agir vive ora no sentido da ação, a partir das trocas com a atividade dos outros e com as outras atividades do próprio sujeito, ora na eficiência, buscando sempre fazer melhor o que já tem sido feito. Nessa dinâmica, ao realizar as tarefas de forma mais eficaz, surgem novas preocupações que colocam em cheque os sentidos já construídos em um círculo virtuoso (CLOT, 2010a).
6 Trecho inspirado em falas proferidas por Clot no III Colóquio Internacional de Clínica da Atividade (III CICA).

\section{Referências}

ALBUQUERQUE, L. G. C. Saúde Mental em Rio Bonito: atividade dos trabalhadores no processo de Reforma Psiquiátrica no Município. 2010. Dissertação (Mestrado) - UFF.

ALLIEZ, E. FEHER, M. Os Estilhaços do capital. In: ALLIEZ, E. FEHER, M. GILLE, D. STENGERS, I. Contratempo. Ensaios sobre algumas metamorfoses do capital. Tradução: Maria de Lourdes Menezes. Rio de Janeiro: ForenseUniversitária, 1988, p. 150-214.

AMADOR, F.S. BARROS, M.E.B. FONSECA, T. M. G. Clínicas do Trabalho e Paradigma Estético. Porto Alegre: Editora da UFRGS, 2016.

BARCA, S. Pão e veneno. Reflexões para uma investigação sobre o 'ambientalismo do trabalho' em Itália, 1968-1998. Laboreal, 6, (2), 10-18, 2010.

BARKER, S. As dramáticas do uso de si de jovens mães trabalhadoras: cartografias do trabalho em insuspeitáveis territórios. 2005. Tese (Doutorado) ENSP, Fiocruz.

BARROS, M. E. B. LOUZADA, A. P. Afirmando a potência de cirandar: cartografia dos processos de produção de saúde na docência. In: BARROS, M. E. B. CARVALHO, S. R. FERIGATO, S. (Org). Conexões: saúde coletiva e políticas de subjetividades. São Paulo: Hucitec, 2009.

BARROS, M. E. B. LOUZADA, A. P. VASCONCELLOS, D. Clínica da Atividade em uma Via Deleuziana: por uma psicologia do trabalho. Informática na educação: teoria \& prática, v. 11, n. 1, 2008.

BENDASSOLLI, P. F. Crítica às apropriações psicológicas do trabalho. Psicologia \& Sociedade, v. 23, n. 1, p. 75-84, 2011.

BRASIL. Ministério da Saúde. Portaria $\mathrm{n}^{\circ} 1.823$, de 23 de agosto de 2012. Institui a Política Nacional de Saúde do Trabalhador e da Trabalhadora. 
CANGUILHEM, G. Meio e normas do homem no trabalho. Pro-posições, v. 12, n. 2-3, p. 109-121, 2001 .

CHAUÍ, M. Cultura e Democracia: o discurso competente e outras falas. São Paulo: Ed. Moderna. 1982.

CLOT, Y. (dir.) Avec Vygotski. Paris, La Dispute, 1999.

CLOT, Y. Entrevista. Cadernos de Psicologia Social do Trabalho, v. 9, n. 2, p. 99-107, 2006.

CLOT, Y. A função psicológica do trabalho. Petrópolis: Vozes, 2007.

CLOT, Y. Entrevista. Mosaico: Estudos em psicologia. V. II, n. 1, p. 65-70, 2008.

CLOT, Y. Trabalho e poder de agir. Belo Horizonte: Fabrefactum, 2010a.

CLOT, Y. A psicologia do trabalho na França e a perspectiva da clínica da atividade. Fractal: Revista de Psicologia, v. 22, n. 1, p. 207-234, 2010b.

CLOT, Y, O ofício como operador de saúde. Cadernos de Psicologia Social do Trabalho, v. 16, n. SPE, p. 1-11, 2013.

CLOT, Y. Prefácio In: ROSEMBERG, D. S. RONCHI FILHO, J. BARROS, M. E. B. (org.) Trabalho docente e poder de agir: Clínica da atividade, devires e análises. Vitória: EDUFES, 2014.

CODO, W. O papel do psicólogo na organização industrial (notas sobre o lobo mau em Psicologia). Psicologia social: O homem em movimento, p. 195202, 1984.

CONCEIÇÃO, C.L. O método de instruções ao sósia no contexto de luta dos trabalhadores pela saúde: uma aposta política no coletivo. 2015. TCC (Curso de especialização em Saúde do Trabalhador e Ecologia Humana) - CESTEH / ENSP / Fiocruz.

FERREIRA, J. P. A restituição de resultados como proposta de pesquisa - intervenção em Saúde do Trabalhador: contribuições para a ampliação do poder de agir de profissionais de enfermagem de hospitais municipais do Rio de Janeiro. 2016. Tese
(Doutorado) - Escola Nacional de Saúde Pública Sergio Arouca, Rio de Janeiro.

LOURAU, R. Análise institucional e práticas de pesquisa. Rio de Janeiro: UERJ, 1993

LOURAU, R. Implicação-transdução. In: ALTOÉ, S. (Org) René Lourau: analista institucional em tempo integral. São Paulo: Hucitec, p. 212-223, 2004.

LOUZADA, A. P. Um trabalho docente: a invenção como imanente à vida. 2009. Tese (Doutorado) - UFES.

MAIA, M. $O$ corpo invisivel do trabalho: cartografia dos processos de trabalho em saúde. 2006. Dissertação (Mestrado) - UFF.

MENDES, R.; DIAS, E. C. Da medicina do trabalho à saúde do trabalhador. Processo Medicina, v. 90, p. 4602-1, 1991.

MINAYO-GOMEZ, C.; DA FONSECA THEDIMCOSTA, S. M. A construção do campo da saúde do trabalhador: percurso e dilemas. [s.l.] Escola Nacional de Saúde Pública, Fundação Oswaldo Cruz, 1997.

MINAYO-GOMEZ, C. Campo da saúde do trabalhador: trajetória, configuração, transformações. In: MINAYO, G. C.; MACHADO, J.M.H.; PENA, P. G. L.(orgs) Saúde do trabalhador na sociedade contemporânea. Rio de Janeiro, Editora Fiocruz. 2011. Pp 23-34.

ODDONE, I. Reflexiones sobre el modelo obrero italiano. Revista Sindical Salud, Trabajo y Medio Ambiente. v 2, n.5. p. 4-8, 2007.

OSÓRIO, C.; CLOT, Y. L'analyse collective des accidents du travail: Une méthode d'analyse pour intégrer la dimension subjective et développer le genre professionnel. Activités Revue Electronique, 7, p.28 - 41. 2010.

OSÓRIO-DA-SILVA, C.; ZAMBONI, J. BARROS, M.E.B. Clínicas do trabalho e análise institucional. Rio de Janeiro, Nova Aliança. 2016.

OSÓRIO-DA-SILVA, C.; RAMMINGER, T. O trabalho como operador de saúde. Revista Ciência \& Saúde Coletiva, v. 19, n. 12, 2014. P. 4751-4758. 
A clínica da atividade no Brasil: por uma outra psicologia do trabalho

OSORIO DA SILVA, C. A fotografia como uma marca do trabalho: um método que convoca o protagonismo do trabalhador na invenção de mundo. In: ZANELLA, A. V. TITTONI, J. Imagens no pesquisar: experimentações. Porto Alegre: Dom Quixote editora. p. 211-226, 2011.

OSORIO DA SILVA, C. Pesquisa e intervenção em clínica da atividade: a análise do trabalho em movimento. In: BENDASSOLLI, P.F. SOBOLL, L.A.P. Métodos de pesquisa e intervenção em psicologia do trabalho: clínicas do trabalho. São Paulo: Atlas, p. 83-99, 2014.

OSORIO DA SILVA, C. Pesquisa e intervenção: movimentos que se cruzam e coexistem, em mutua interferência. In: BANKS-LEITE, L. SMOLKA, A. L. B. ANJOS, D. D. (org.) Diálogos na perspectiva histórico-cultural: interlocuções com a clínica da atividade. Campinas, SP: Mercado das Letras, p. 153-168, 2016.

OSORIO DA SILVA, C. BARROS, M. E. B. LOUZADA, A. P. F. Clínica da atividade: dos conceitos às apropriações no Brasil. In: BENDASSOLLI, P.F. SOBOLL, L.A.P (org.) Clínicas do Trabalho: novas perspectivas para compreensão do trabalho na atualidade. São Paulo: Atlas, 2011.
OSORIO, C. MACHADO, J. MINAYO-GOMEZ, C. Proposição de um método de análise coletiva dos acidentes de trabalho no hospital. Cadernos de Saúde Pública, Rio de Janeiro, n. 21 (2), p. 517524, 2005.

SAMPAIO, J. R. Psicologia do trabalho em três faces. In: GOULART, I. B. Psicologia do trabalho $e$ gestão de recursos humanos: estudos contemporâneos. São Paulo: Casa do Psicólogo, p. 19-40, 1998.

SANTORUM, K. M. T. Pelas fendas do trabalho vivo: textos, contextos e efeitos na atividade de vigilância em saúde do trabalhador. 2006. Tese (Doutorado) - ENSP/ Fiocruz.

TEIXEIRA, D. V.; BARROS, M. E. B. Clínica da atividade e cartografia: construindo metodologias de análise do trabalho. Psicologia \& Sociedade; v.21, n. 1, p. 81-90, 2009.

ZANELLI, J. C., \& BASTOS, A. V. B. Inserção profissional do psicólogo em organizações e no trabalho. In: J. C. ZANELLI, J. E.; BORGESANDRADE, \& BASTOS, A. V. B. (Orgs.) Psicologia, Organizações e Trabalho no Brasil. Porto Alegre: Artmed, 2004. p. 466- 491.

\section{Sobre os autores:}

Cristiane Lisbôa da Conceição é psicóloga, especialista em Saúde do Trabalhador e Ecologia Humana pelo CESTEH/ENSP/Fiocruz e mestre em Psicologia pela Universidade Federal Fluminense.

Roberta Pereira Furtado da Rosa é docente do curso de Terapia Ocupacional no IFRJ. Doutoranda do programa de pós-graduação em Psicologia da Universidade Federal Fluminense.

Claudia Osório da Silva é psicóloga, mestre e doutora em Saúde Pública pela Fundação Oswaldo Cruz. Docente do Departamento de Psicologia da Universidade Federal Fluminense.

Recebido em julho de 2017.

Aprovado em novembro de 2017. 